ISSN: 2386-3919 - e-ISSN: 2386-3927

DOI: https://doi.org/10.14201/et2018361151178

\title{
INFLUENCIA DE LA ORGANIZACIÓN ESCOLAR EN LA EDUCACIÓN DE LOS ALUMNOS DE ALTAS CAPACIDADES
}

\section{Influence of school organization on the education of gifted students}

L. PÉrez Díez y C. Jiménez Fernández

Recibido: 8.11.2017; Aceptado: 10.1.2018; Publicado: 30.06.2018

Ref. Bibl. L. PÉREZ DÍEZ y C. JIMÉNEZ FERNÁNDEZ. Influencia de la organización escolar en la educación de los alumnos de altas capacidades. Enseñanza $\varepsilon$ Teaching, 36, 1-2018, 151-178.

RESUMEN: La intervención educativa con los alumnos de altas capacidades se produce en el marco de una estructura organizativa que la condiciona ya que puede dificultar la puesta en práctica de propuestas destinadas a dar respuesta a las especiales necesidades educativas que presentan. Esta investigación tiene la finalidad de describir qué forma o formas pueden adoptar las posibilidades y obstáculos para el desarrollo óptimo de la intervención con los alumnos de altas capacidades desde la perspectiva de la estructura organizativa del sistema educativo y los centros que lo componen. Para ello, se ha construido un cuestionario destinado al profesorado de educación primaria de la provincia de Palencia para que ponga de manifiesto su percepción acerca de la educación que reciben los más capaces atendiendo a la normativa educativa en materia de atención a la diversidad, al agrupamiento del alumnado, a la organización del profesorado, a los espacios y los tiempos educativos. Los resultados indican que los centros que conforman el sistema educativo poseen una estructura organizativa rígida que difícilmente se adapta a la intervención con estos alumnos y que los normaliza, los asimila al perfil del alumno medio sin dar una respuesta satisfactoria a sus necesidades educativas. Es necesario profundizar en las características y peculiaridades del marco organizativo que sustenta la práctica educativa para adecuarlo a las necesidades que presentan los alumnos de altas capacidades. Para ello, es necesario que el profesorado conozca quiénes son y cómo 
L. PÉREZ DÍEZ Y C. JIMÉNEZ FERNÁNDEZ

INFLUENCIA DE LA ORGANIZACIÓN ESCOLAR EN LA EDUCACIÓN

DE LOS ALUMNOS DE ALTAS CAPACIDADES

aprenden estos alumnos, y qué posibilidades y límites ofrece la normativa en la que se sustenta la práctica educativa basada en los principios de atención a la diversidad e inclusividad.

Palabras clave: altas capacidades; atención a la diversidad; estructura organizativa de los centros; intervención educativa; opiniones del profesorado; sistema educativo.

SUMMARY: Educational intervention for high intellectual potential students takes place in the framework of an organizational structure which has an influence thereon since it can hinder the implementation of proposals aimed at meeting the special educational needs that these students have. The purpose of this research is to describe the form or forms that the possibilities or barriers concerning the optimal development of an intervention for high intellectual potential students may take from the perspective of the organizational structure of the education system and its component institutions. To this end, a questionnaire aimed at primary education teachers in the province of Palencia has been drawn up in such a manner that they can express their views on the education received by the most talented students on the basis of education regulations concerning attention to diversity, grouping of students, organization of teachers and educational areas and hours. The results show that the institutions that make up the education system have a rigid organizational structure, which poorly adapts to intervention for these students and which standardizes them and assimilates them to average students without providing a satisfactory response to their educational needs. It is necessary to delve into the characteristics and specificities of the organizational framework upon which educational practice is based in order to bring it into line with the needs of high intellectual potential students. To do so, teachers need to understand who these students are and how they learn, as well as the possibilities and limits of the regulations that underpin the educational practice based on the principles of attention to diversity and inclusiveness.

Key words: high intellectual potential; attention to diversity; organizational structure of institutions; educational intervention; view of teachers; education system.

\section{INTRODUCCIÓN}

En la sociedad actual el conocimiento es probablemente el factor más importante de los procesos económicos, sociales y educativos. En este contexto, el desarrollo del talento se ha convertido en un objetivo prioritario de la educación y es una condición indispensable para liderar la innovación y el desarrollo comunitario. Por otra parte, la buena educación siempre se ha preocupado de desarrollar la capacidad y el talento de sus alumnos.

El presente estudio pretende conocer la opinión de una muestra de profesores de Educación Primaria (EP) sobre la educación de los estudiantes más capaces, 
particularmente sobre si las estructuras organizativas dominantes en los centros educativos son adecuadas para intervenir con ellos. O si, por su propia inercia, tienden a normalizar, a conducir hacia la media los comportamientos específicos de estos alumnos haciendo que converjan en sus planteamientos y retos con el alumno medio, cuyo número predomina en los centros y aulas. Es un tema complejo, de equidad en la educación.

En las páginas que siguen procederemos del modo siguiente. En primer lugar, presentaremos las ideas básicas sobre la normativa legal que regula la educación de los más capaces. En segundo lugar, esbozaremos la organización escolar imperante en los centros escolares desde la perspectiva de la diversidad de los más capaces. Finalmente reflejaremos el proceso seguido en la elaboración de un cuestionario ad hoc y los resultados obtenidos al aplicarlo a una muestra de profesores de la provincia de Palencia. El cuestionario pretende reflejar sus valoraciones sobre la interrelación entre las estructuras organizativas de los centros educativos y la intervención práctica con los alumnos de altas capacidades, tratando de encontrar los puntos fuertes y débiles de dicha interrelación.

\section{EdUCACIÓN DE LOS MÁS CAPACES}

Abordamos la educación de los más capaces preguntándonos cómo contempla la legislación educativa a estos alumnos, quiénes son y cómo aprenden y qué elementos de los que conforman la estructura organizativa de los centros educativos inciden especialmente en su educación.

\subsection{Normativa, diagnóstico y educación de los más capaces}

Nos referiremos a los aspectos reflejados en la Ilustración 1 y que son una de las bases para la construcción del cuestionario y para orientar las respuestas del profesorado al contestarlo. 
ILUSTRACIÓN 1

Elementos considerados en la educación de los alumnos de altas capacidades

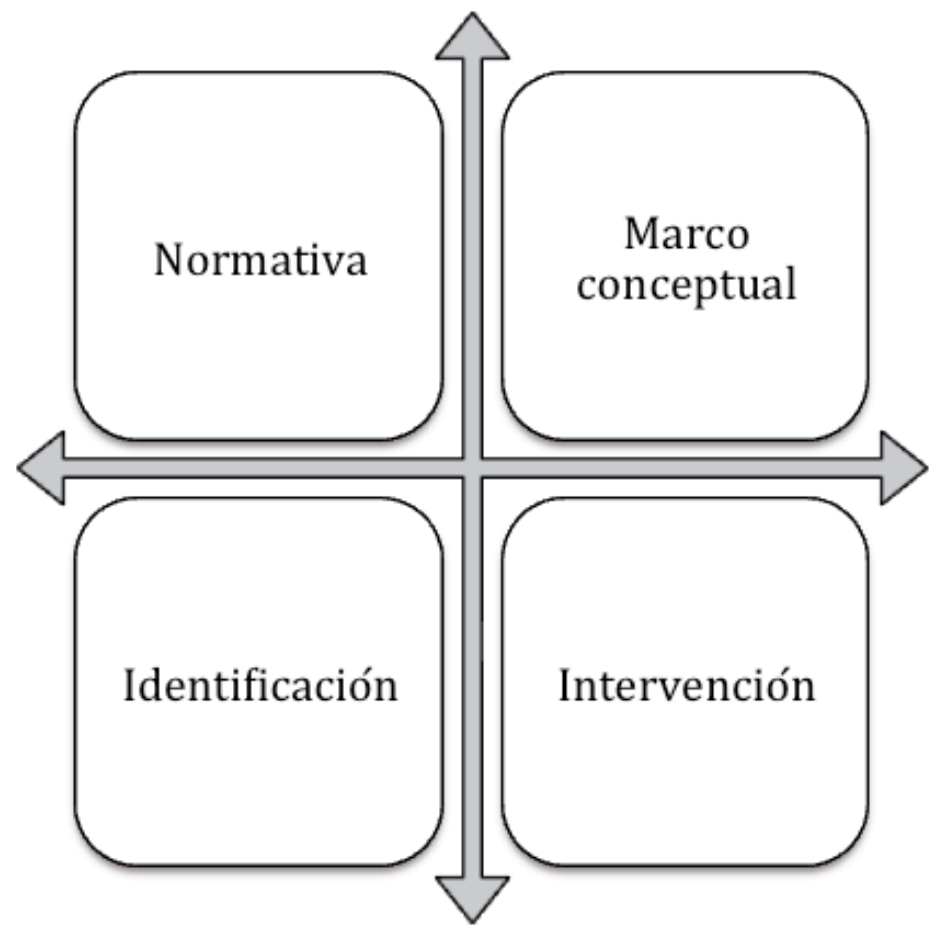

En el sistema educativo español la educación de los alumnos más capaces, como la del conjunto de los estudiantes, se fundamenta en los principios de inclusión y atención a la diversidad. Y aunque no establece una conceptualización explícita de la alta capacidad, tomando como referencia el principio de atención a la diversidad en el marco de una escuela inclusiva, se plantea como objetivo el máximo desarrollo de las capacidades de todos los alumnos (LOE, 2006; LOMCE, 2013).

La Tabla 1 resume la normativa estatal y autonómica referida a la regulación de la EP y la atención a la diversidad y la inclusión educativa en España y en Castilla y León. 
L. PÉREZ DÍEZ Y C. JIMÉNEZ FERNÁNDEZ

INFLUENCIA DE LA ORGANIZACIÓN ESCOLAR EN LA EDUCACIÓN

DE LOS ALUMNOS DE ALTAS CAPACIDADES

TABLA 1

Referentes normativos del estudio

\begin{tabular}{|c|c|c|}
\hline & LEYES BÁSICAS DE EP & $\begin{array}{l}\text { DESARROLLO NORMATIVO DE LA ATENCIÓN } \\
\text { A LA DIVERSIDAD E INCLUSIVIDAD }\end{array}$ \\
\hline \multirow{3}{*}{ 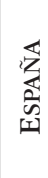 } & \multicolumn{2}{|c|}{ Ley Orgánica de Educación (2006) } \\
\hline & \multicolumn{2}{|c|}{ Ley Orgánica de Mejora de la Calidad del Sistema Educativo (2013) } \\
\hline & Currículo básico de EP (2014) & Flexibilización educativa (2003) \\
\hline 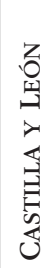 & $\begin{array}{l}\text { Currículo de EP según la } \\
\text { LOMCE (2014) } \\
\text { Autonomía de los centros } \\
\text { docentes (2014) }\end{array}$ & $\begin{array}{l}\text { * Plan de atención al alumnado con superdotación } \\
\text { intelectual (2003) } \\
\text { * Flexibilización educativa (2004) } \\
\text { * Respuesta educativa al alumnado con necesidades } \\
\text { específicas de apoyo educativo (2010) } \\
\text { * Implantación, evaluación y desarrollo de la EP (2014) }\end{array}$ \\
\hline
\end{tabular}

Autores como Hernández Torrano y Gutiérrez Sánchez (2014) consideran que las leyes orgánicas tendrían que ser más explícitas al referirse a la conceptualización, diagnóstico e intervención con estos alumnos, y que las administraciones educativas deberían explicitar los perfiles intelectuales que engloba la alta capacidad, así como el porqué de las denominaciones escogidas.

En el currículo básico de EP (2014) se concreta su desarrollo a través de medidas curriculares y organizativas y de otras como la flexibilización temporal en el acceso a los niveles educativos.

Como en otras comunidades autónomas, en la de Castilla y León se han producido iniciativas legislativas encaminadas a desarrollar la educación de los más capaces. Es destacable el plan de atención al alumnado con superdotación intelectual (2005) que articula la respuesta educativa a estos alumnos y permite la creación de recursos diferenciados como los equipos específicos para su atención (2007).

Sin embargo, estas medidas no han repercutido significativamente en la educación de los más capaces. Los porcentajes de identificación de estos alumnos apenas han variado entre los cursos 2003/2004 y 2012/2013, y están lejos de alcanzar los valores recomendados. 
GRÁFICO 1

Porcentajes de identificación de alumnos de altas capacidades en la Comunidad de Castilla y León

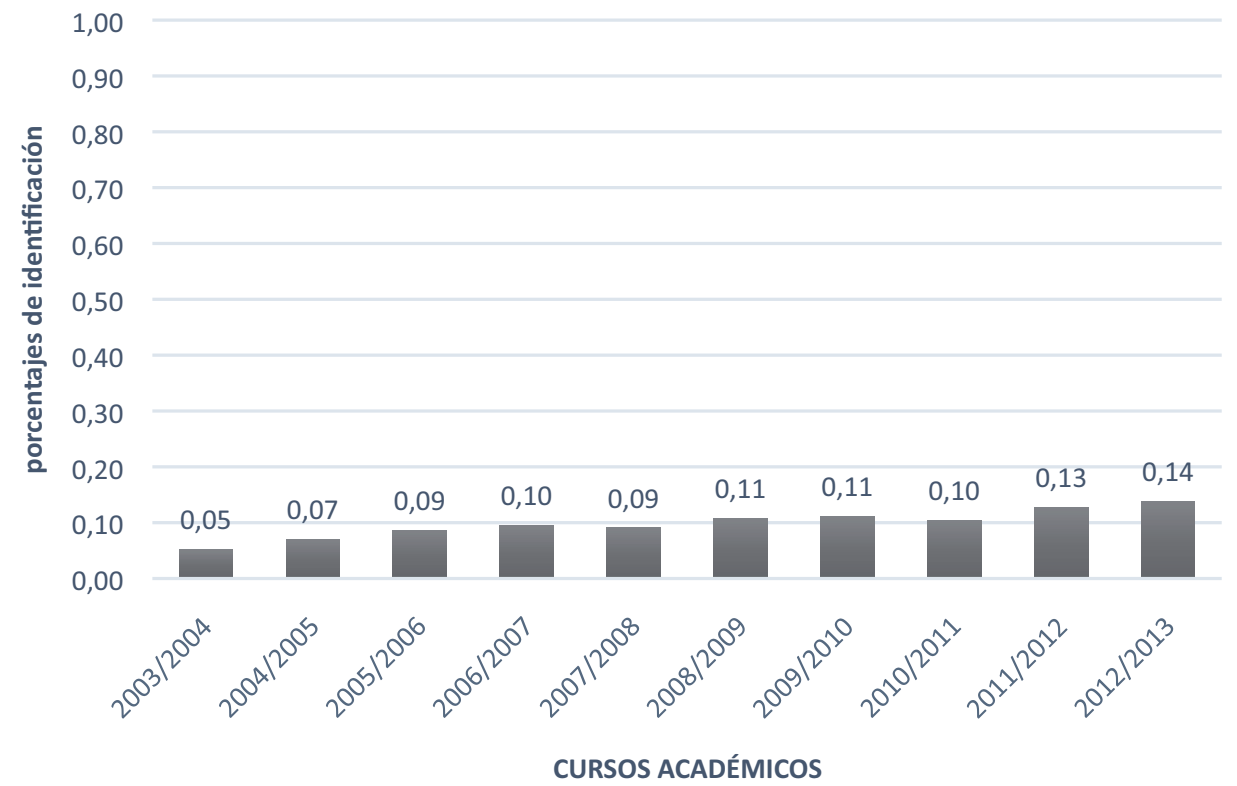

La Tabla 2, elaborada como el Gráfico 1 de las Estadísticas de la educación no universitaria del Ministerio de Educación, Cultura y Deporte, muestra cómo han evolucionado estas cifras en la educación obligatoria. En el curso 2014-2015, la media nacional de alumnos diagnosticados con alta capacidad ascendió al 0,35\% y al 0,25\% en Castilla y León, en ambos casos alejadas de las estimaciones recomendadas para estos niveles educativos. 
INFLUENCIA DE LA ORGANIZACIÓN ESCOLAR EN LA EDUCACIÓN

DE LOS ALUMNOS DE ALTAS CAPACIDADES

TABLA 2

Alumnos con alta capacidad identificados en el curso 2014/2015 en España y CC. AA.

\begin{tabular}{|c|c|c|c|}
\hline \multirow{2}{*}{$\begin{array}{c}\text { CC. AA. } \\
\text { CuRSO 2014/2015 }\end{array}$} & \multirow{2}{*}{ N. $^{\text {TOTAL DE ALUMNOS }}$} & \multicolumn{2}{|c|}{ ALUMNOS CON ALTA CAPACIDAD } \\
\cline { 3 - 4 } & & $\mathbf{N}$ & $\%$ \\
\hline Andalucía & 955543 & 7150 & 0,75 \\
\hline Aragón & 124850 & 90 & 0,07 \\
\hline Asturias & 79722 & 539 & 0,68 \\
\hline Baleares & 111478 & 455 & 0,41 \\
\hline Canarias & 215381 & 1641 & 0,76 \\
\hline Cantabria & 53254 & 106 & 0,20 \\
\hline Castilla y León & 210028 & 519 & 0,25 \\
\hline Castilla La Mancha & 218472 & 275 & 0,13 \\
\hline Cataluña & 775587 & 171 & 0,02 \\
\hline C. Valenciana & 508760 & 64 & 0,01 \\
\hline Extremadura & 110341 & 163 & 0,15 \\
\hline Galicia & 224257 & 1069 & 0,48 \\
\hline Madrid & 661453 & 1642 & 0,25 \\
\hline Murcia & 175214 & 2776 & 1,58 \\
\hline Navarra & 66006 & 253 & 0,38 \\
\hline País Vasco & 204170 & 280 & 0,14 \\
\hline La Rioja & 31317 & 124 & 0,40 \\
\hline Ceuta & 11701 & 3 & 0,03 \\
\hline Melilla & 11752 & 8 & 0,07 \\
\hline España & 4749286 & 0,35 \\
\hline
\end{tabular}

En cuanto a la conceptualización, desde el punto de vista del aprendizaje cabe definirlos como aquellos que aprenden a mayor ritmo, con mayor profundidad y mayor amplitud que sus iguales, sobre todo si trabajan en temas que atraen su interés y si encuentran en padres y profesores el apoyo y la guía adecuados.

Las diversas acepciones utilizadas, como superdotado, talentoso, sujeto con altas capacidades, potencialmente dotado, alumnos más capaces, o incluso alumno precoz, prodigio o genio, a veces han generado confusión y hasta conflicto entre los usos teóricos y prácticos del término (Walker, Shore y French, 2011). La diferencia entre unas acepciones y otras suele ser de matiz. La idea central que subyace a todas ellas es que, al enfrentarse al aprendizaje, la alta manifestación de una o más capacidades produce diferencias cualitativas y cuantitativas entre la persona que la posee y su grupo de referencia (Mandelman, Tan, Aljughaiman y Grigorenko, 2010). 
L. PÉREZ DÍEZ Y C. JIMÉNEZ FERNÁNDEZ

INFLUENCIA DE LA ORGANIZACIÓN ESCOLAR EN LA EDUCACIÓN

DE LOS ALUMNOS DE ALTAS CAPACIDADES

Teniendo en cuenta la amplitud de las conceptualizaciones y que suelen estar apoyadas en distintas teorías sobre la inteligencia humana, lo razonable es partir de una concepción amplia y pluridimensional de la alta capacidad (Renzulli y Gaesser, 2015); considerar los efectos que sobre ella producen los ambientes en los que se desenvuelven, sin esperar que un estudiante determinado reúna todas las características que los estudiosos han ido aportando (Freeman, 2015); considerar varios criterios, y tener en cuenta que la alta capacidad se da en todos los contextos sociales y culturales.

Orientadores y profesores demandan indicadores que les ayuden a ser equitativos y eficaces con todos los alumnos. Aunque tal demanda parezca razonable, dado que en nuestro país cada vez un mayor número de padres plantean a los centros la exigencia de un diagnóstico de la alta capacidad de sus hijos, la respuesta a esta cuestión no puede ser unívoca. Depende del fin que se persiga al establecer un punto de corte, de los recursos disponibles para atender a los seleccionados, de las tradiciones imperantes en un contexto dado y de la concepción subyacente en último término sobre las personas con alta capacidad. La Tabla 3 recoge estimaciones de los porcentajes a esperar respecto de la población escolar:

TABLA 3

Estimaciones sobre porcentajes de alumnos con alta capacidad

\begin{tabular}{|c|c|}
\hline Autores E Instituciones & Porcentajes \\
\hline Comité Económico y Social (2012) & $5-10 \%$ \\
\hline Renzulli (2003) & $15-20 \%$ \\
\hline Gagné (2015) & $10 \%$ \\
\hline
\end{tabular}

Las palabras de Gagné (2015) ilustran esta cuestión:

La pregunta "cuántos» no tiene una respuesta absoluta; en ninguna parte vamos a encontrar un número mágico que separe automáticamente los etiquetados con alta capacidad o con talento del resto de la población. El establecimiento de un umbral adecuado requiere que los profesionales lleguen a un acuerdo.

Como en otros campos, es importante saber cuántos alumnos de altas capacidades cabe esperar razonablemente pues los valores umbrales pueden ayudar a identificar una proporción adecuada. Por ejemplo, una identificación fundamentada en una concepción restrictiva de la alta capacidad puede dar lugar a sesgos y a baja representación de las minorías en los programas educativos destinados a desarrollar la capacidad y el talento (Renzulli y Gaesser, 2015). Al mismo tiempo hay que vigilar los sesgos sistemáticos que vienen colándose en estas estimaciones al referirlas a los grupos étnicos y al género. Las niñas y las mujeres han estado y están subrepresentadas apoyándose en tradiciones culturales más que en indicadores objetivos. Desde finales del pasado siglo las estadísticas del Ministerio de 
Educación vienen mostrando sistemáticamente el superior rendimiento académico de las niñas y de las mujeres en los diferentes niveles del sistema educativo.

En cuanto al tipo de intervención educativa más adecuada para estos alumnos el aspecto fundamental para tener en cuenta es que esta tiene que ser coherente con las características específicas de los alumnos previamente identificadas (Mandelman, Tan, Aljughaiman y Grigorenko, 2010). Renzulli y Gaeser (2015) indican que dicha coherencia puede considerarse la regla de oro de la educación de estos alumnos. Por su parte, Brody (2015) plantea que, si los programas diseñados para estos alumnos no van dirigidos a sus características específicas, fracasarán en su intento de atender a sus necesidades académicas y personales.

Puede hablarse de tres modelos básicos de intervención con variaciones dentro y entre ellos: aceleración, enriquecimiento y agrupamiento por capacidad.

La aceleración modifica la edad en la que el alumno cursa el currículo que le corresponde por su edad cronológica para adecuar la intervención educativa a sus capacidades y ritmo de aprendizaje. Puede adquirir formas como la admisión precoz o el salto de curso.

Una de las mayores preocupaciones de educadores, padres y estudiantes respecto a esta medida está relacionada con la posible inmadurez psicológica del estudiante y la separación de los compañeros de su misma edad. Es conveniente valorar si al alumno le compensa el desafío intelectual frente a la posible frustración social por estar con alumnos de edad superior.

Las investigaciones constatan que, salvo excepción, no hay problemas de este tipo asociados a la aceleración, sino que produce pequeños y moderados beneficios socioemocionales además de los académicos (Steenbergen-Hu y Luna, 2011).

El enriquecimiento consiste en planificar y llevar a la práctica aprendizajes más ricos y variados y exigiendo al estudiante que presente como resultados del aprendizaje productos más complejos en el fondo y más divergentes en la forma. Según dónde se ponga el énfasis, se habla de enriquecimiento orientado al contenido, enriquecimiento orientado al proceso y enriquecimiento orientado al producto.

Finalmente, el agrupamiento puede ser homogéneo o trabajar con estudiantes de similar capacidad, y heterogéneo o trabajar con el grupo ordinario que presenta una mayor gama de habilidades. Y puede tener carácter fijo o durante toda la jornada y curso escolar, o a tiempo parcial, reunirse en determinados periodos del horario escolar y para determinadas tareas dentro o fuera del aula ordinaria.

Los estudios de metaanálisis de Kulik (2002) distinguen entre el agrupamiento homogéneo por capacidad con carácter fijo a lo largo del año escolar o a tiempo parcial, es decir, en parte del horario escolar. Concluye que en el caso de los alumnos más capaces el agrupamiento por capacidad en cualquiera de sus modalidades es más eficaz que el agrupamiento heterogéneo, considerando como variables criterio el rendimiento escolar y la motivación académica de los alumnos.

Otros estudios de metaanálisis (Steenbergen, Makel y Olszewski-Kubilius; 2016) ponen de manifiesto que los efectos de la agrupación especial para alumnos de altas capacidades son positivos, moderados y estadísticamente significativos. 
Por su parte, Adelson, McCoah y Gavin (2012) afirman que el agrupamiento por capacidad no produce mejoras académicas en los estudiantes de altas capacidades y obstaculizan el aprendizaje de los estudiantes normales.

Otros investigadores han encontrado que los agrupamientos homogéneos benefician a los estudiantes en todos los niveles de habilidad (Michael, Matthews, Ritchotte y McBee, 2013) y en especial a los alumnos de altas capacidades, que presentan un mayor rendimiento académico y la posibilidad de intervenir con un tipo de necesidades educativas específicas (Walker, Shore y French, 2011).

Respecto a los agrupamientos heterogéneos, Walker, Shore y French (2011) concluyen que se produce un bajo rendimiento escolar ya que disminuye la motivación al plantearles tareas demasiado fáciles para unos o demasiado difíciles para otros. En consecuencia, se produce un progreso limitado de los alumnos más capaces.

\section{ESTRUCTURA ORGANIZATIVA DE LOS CENTROS Y ATENCIÓN A LOS MÁS CAPACES}

Los centros que conforman el sistema educativo asientan su práctica en una estructura organizativa en la que se relacionan los miembros de la comunidad educativa y que está influida por elementos del entorno (Cardona Andújar, 2008). Esta estructura organizativa es básica porque sin los recursos personales y materiales necesarios, sin una previsión de los espacios y de la distribución del tiempo es prácticamente imposible desarrollar actividades en un marco organizativo (Gairín y Rodríguez Gómez, 2011). La flexibilidad de dicha estructura cobra especial relieve desde el marco de la atención a la diversidad, de los alumnos más capaces en este caso.

Como señala Pérez Pérez (2014) la naturaleza de la organización escolar condiciona su aptitud para el cambio. Una organización pesada y rígida tiene como consecuencia un inmovilismo que se traduce en escasas transformaciones organizativas que dificultan su adaptación a las nuevas dinámicas sociales y a la diversidad de los alumnos y de los profesores.

Dentro de la estructura organizativa abordamos los siguientes elementos: agrupamiento del alumnado, organización del profesorado, espacios y tiempos, que sirven de orientación en la elaboración del cuestionario y que se recogen en la siguiente ilustración: 
ILUSTRACIÓN 2

Elementos de la estructura organizativa seleccionados para conocer su influencia en la educación de los alumnos de altas capacidades

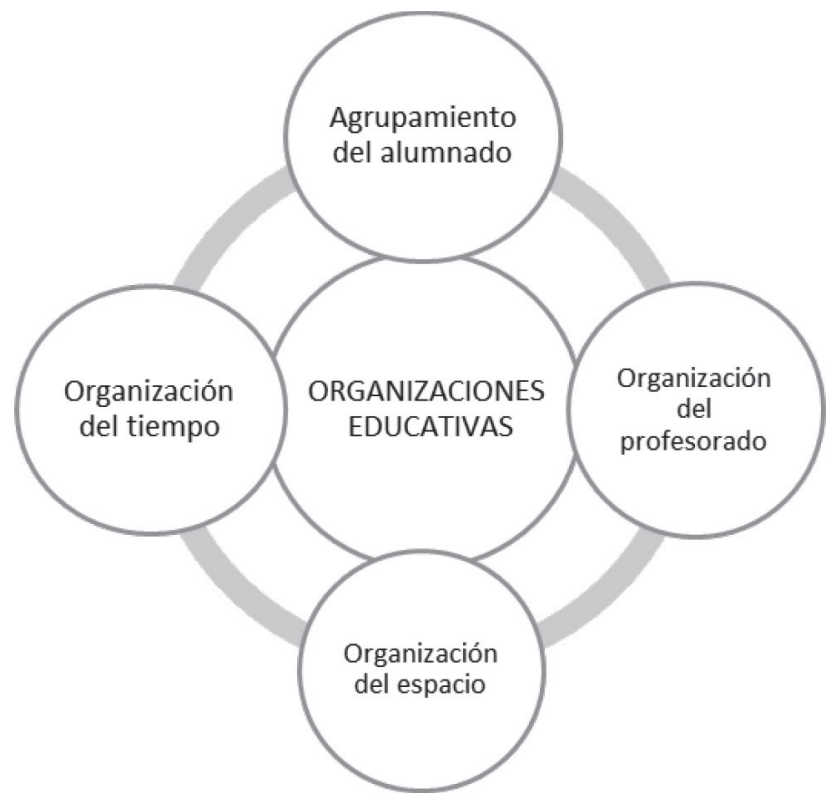

\subsection{Agrupamiento del alumnado}

Su importancia radica en la influencia que tiene en el rendimiento académico (Calatayud Salom, 2014), las expectativas sobre igualdad de oportunidades (PISA, 2012) y la superación o mejora del fracaso y abandono escolar (INCLUD-ED, 2015), fundamentalmente.

La influencia de los agrupamientos en la educación de los más capaces se plantea desde una doble perspectiva: niveles educativos y grupos de enseñanza.

En la Tabla 4 se exponen posibilidades de agrupamiento de los alumnos más capaces en distintos niveles educativos. 
L. PÉREZ DÍEZ Y C. JIMÉNEZ FERNÁNDEZ

INFLUENCIA DE LA ORGANIZACIÓN ESCOLAR EN LA EDUCACIÓN

DE LOS ALUMNOS DE ALTAS CAPACIDADES

TABLA 4

Agrupamiento del alumnado en la educación de los más capaces tomando como criterio los niveles educativos. Elaboración propia

\begin{tabular}{|c|c|c|c|}
\hline ESCUELA GRADUADA & $\begin{array}{c}\text { ESCUELA NO } \\
\text { GRADUADA }\end{array}$ & $\begin{array}{l}\text { AGRUPAMIENTO } \\
\text { MULTIGRADO }\end{array}$ & Ciclos \\
\hline $\begin{array}{l}\text { Flexibilización de la } \\
\text { programación para } \\
\text { adaptarla al alumno } \\
\text { Individualización } \\
\text { de la enseñanza }\end{array}$ & $\begin{array}{l}\text { Agrupamientos } \\
\text { flexibles } \\
\text { Programas flexibles } \\
\text { y adaptables } \\
\text { Enseñanza } \\
\text { cooperativa } \\
\text { Progresión del } \\
\text { alumno relacionada } \\
\text { con su avance } \\
\text { en el proceso } \\
\text { de aprendizaje }\end{array}$ & $\begin{array}{l}\text { Propuesta curricular } \\
\text { con niveles de } \\
\text { dificultad y con } \\
\text { elementos de } \\
\text { profundización } \\
\text { Progreso del } \\
\text { alumno según su } \\
\text { ritmo y capacidades } \\
\text { Previsión de } \\
\text { las diferencias } \\
\text { individuales }\end{array}$ & $\begin{array}{l}\text { La organización } \\
\text { de las actividades } \\
\text { posibilita } \\
\text { profundizar en } \\
\text { los contenidos } \\
\text { de las áreas } \\
\text { Posibilidad de } \\
\text { progresar dentro } \\
\text { del ciclo según } \\
\text { capacidades y ritmo } \\
\text { de aprendizaje }\end{array}$ \\
\hline
\end{tabular}

Recordemos que en el marco de la atención a la diversidad y de la escuela inclusiva todos los alumnos tienen derecho a un ambiente educativo flexible, adaptado a su ritmo de aprendizaje.

\subsection{Organización del profesorado}

El profesorado se organiza para desarrollar funciones asociadas a la estructura orgánica de los centros educativos: jerarquía, dependencia orgánica, delegación, toma de decisiones, seguimiento de acuerdos (Antúnez y Gairín, 1996). Los cambios sociales y culturales hacen necesario compartir el conocimiento y así poder profundizar en todas las áreas del currículo (Aznar, Cáceres e Hinojo, 2014).

En esta investigación se ha optado por dividir en dos tipos las formas en las que el profesorado se organiza: relaciones orgánicas y educativas. La Tabla 5 resume la posible incidencia de las relaciones orgánicas en la educación de los alumnos de altas capacidades. 
L. PÉREZ DÍEZ Y C. JIMÉNEZ FERNÁNDEZ

INFLUENCIA DE LA ORGANIZACIÓN ESCOLAR EN LA EDUCACIÓN

DE LOS ALUMNOS DE ALTAS CAPACIDADES

TABLA 5

Relaciones orgánicas y su posible incidencia en la educación de los alumnos de altas capacidades. Elaboración propia

\begin{tabular}{|c|c|c|}
\hline ÓRGANO & FUNCIÓN & $\begin{array}{l}\text { INCIDENCIA EN LA EDUCACIÓN } \\
\text { DE LOS MÁS CAPACES }\end{array}$ \\
\hline Equipo Directivo & Liderazgo institucional & $\begin{array}{l}\text { Impulso y diseño de planes } \\
\text { para la educación de los más } \\
\text { capaces con la colaboración del } \\
\text { profesorado } \\
\text { Obtención de recursos para la } \\
\text { educación de los más capaces } \\
\text { Valoración de los resultados de } \\
\text { la puesta en práctica de dichos } \\
\text { planes }\end{array}$ \\
\hline Consejo Escolar & $\begin{array}{l}\text { Representación y participación } \\
\text { de los miembros de la } \\
\text { comunidad educativa }\end{array}$ & $\begin{array}{l}\text { Adopción de acuerdos de } \\
\text { actuación en la educación de } \\
\text { los más capaces }\end{array}$ \\
\hline Claustro & Participación del profesorado & $\begin{array}{l}\text { Proponer iniciativas que incidan } \\
\text { en distintos aspectos de la } \\
\text { educación de los más capaces: } \\
\text { orientación, tutoría, innovación, } \\
\text { actividades complementarias }\end{array}$ \\
\hline $\begin{array}{l}\text { Departamentos } \\
\text { Didácticos }\end{array}$ & $\begin{array}{l}\text { Coordinación vertical de las } \\
\text { actuaciones del profesorado }\end{array}$ & $\begin{array}{l}\text { Propuestas de enriquecimiento } \\
\text { de las asignaturas del currículo }\end{array}$ \\
\hline Equipos educativos & $\begin{array}{l}\text { Adecuar las intervenciones del } \\
\text { profesorado a las posibilidades } \\
\text { del alumnado }\end{array}$ & $\begin{array}{l}\text { Reorganización de los recursos } \\
\text { y de los agrupamientos para } \\
\text { favorecer la educación de los } \\
\text { más capaces }\end{array}$ \\
\hline
\end{tabular}

Respecto a las relaciones educativas, la Tabla 6 muestra cuál puede ser su incidencia en la educación de los más capaces. 
L. PÉREZ DÍEZ Y C. JIMÉNEZ FERNÁNDEZ

INFLUENCIA DE LA ORGANIZACIÓN ESCOLAR EN LA EDUCACIÓN

DE LOS ALUMNOS DE ALTAS CAPACIDADES

TABLA 6

Relaciones educativas del profesorado y posible respuesta al alumnado de altas capacidades. Elaboración propia

\begin{tabular}{|l|l|l|}
\hline $\begin{array}{c}\text { ORGANIZACIÓN } \\
\text { DEL PROFESORADO }\end{array}$ & INTERVENCIÓN EDUCATIVA & \multicolumn{1}{|c|}{$\begin{array}{c}\text { INCIDENCIA EN LA EDUCACIÓN } \\
\text { DE LOS MÁS CAPACES }\end{array}$} \\
\hline Equipos cooperativos & $\begin{array}{l}\text { Flexibilización en el } \\
\text { agrupamiento }\end{array}$ & $\begin{array}{l}\text { Mayor ajuste a las necesidades de } \\
\text { los alumnos más capaces }\end{array}$ \\
\hline Equipos $a d$ hoc & $\begin{array}{l}\text { Resolución de situaciones } \\
\text { organizativas que afectan } \\
\text { a los más capaces }\end{array}$ & $\begin{array}{l}\text { Selección de los profesores más } \\
\text { adecuados para resolver dichas } \\
\text { situaciones: especialistas, orientador, } \\
\text { profesores con formación específica }\end{array}$ \\
\hline Equipos verticales & $\begin{array}{l}\text { Desarrollo del currículo } \\
\text { a diferentes niveles } \\
\text { educativos }\end{array}$ & $\begin{array}{l}\text { Ubicación de la propuesta educativa } \\
\text { en nivel educativo adecuado para } \\
\text { dar respuesta a los estudiantes de } \\
\text { altas capacidades }\end{array}$ \\
\hline
\end{tabular}

La tecnología digital omnipresente en la sociedad en red también ha irrumpido en la escuela aunque en esta el ritmo de incorporación es más lento que el que se produce en los cambios tecnológicos (Tourón y Santiago, 2015). Para los alumnos de altas capacidades, la tecnología y el trabajo en red ofrecen la posibilidad real de dar una respuesta educativa individualizada que les permite trabajar a su propio ritmo, y que les proporciona retroalimentación permanente sobre lo que están aprendiendo (Román González, 2014).

El aprendizaje personalizado, cuyo objetivo es responder a las necesidades específicas de aprendizaje, intereses, aspiraciones y contextos culturales de los alumnos más capaces (y de todos los alumnos) es apoyado por diferentes tecnologías y tendencias como el aprendizaje híbrido, trae tu propio dispositivo, analíticas de aprendizaje, tecnologías de aprendizaje adaptativo o el aprendizaje en línea.

\subsection{Espacios y tiempos}

El espacio y el tiempo son variables a contemplar en la estructura organizativa de los centros educativos. El espacio hace referencia al edificio escolar y a las aulas, mientras que el tiempo se plantea como una continuidad de tareas diferentes que hacen referencia a un horario (Antúnez y Gairín, 1996). Las necesidades generadas en la práctica educativa han hecho evolucionar el edificio escolar desde modelos organizados en torno al grupo de alumnos o al conjunto de materias, hasta modelos más flexibles que posibilitan desarrollar entornos adaptados a dichas necesidades. Igualmente, la configuración espacial del aula debe realizarse desde una perspectiva flexible que priorice la actividad del alumno, sus conocimientos previos, la colaboración. 
En el tiempo escolar existen criterios que determinan la estructura y duración de las unidades temporales: calendario, horario, sesión. Estas unidades temporales deben surgir de las necesidades de la actividad educativa y no de un esquema temporal previamente establecido.

La organización del tiempo del alumnado tiene que tener en cuenta sus necesidades educativas y no basarse exclusivamente en elementos como las programaciones y las materias (Domenech y Viñas, 1997). Estas consideraciones pueden tener consecuencias significativas para los alumnos más capaces. Los horarios cerrados y establecidos de antemano propician un ritmo de trabajo estable y artificial que les "normaliza» al no beneficiar su ritmo más rápido de aprendizaje.

Opciones más acordes a la forma de aprendizaje de los más capaces son: flexibilidad en la construcción de los horarios, alternativas a programas de trabajo uniformes e invariables para todo el curso, alteración de la duración de las unidades de trabajo y posibilitar que los alumnos tengan la oportunidad de organizar parcialmente su tiempo.

El tiempo del profesorado está condicionado por la distribución con criterios uniformes que la administración educativa hace de él. De hecho, la administración define los tiempos en función de la terminación de tareas y del cumplimiento de horarios, desconociendo en muchas ocasiones el contexto y las necesidades de los centros educativos. En ellos, los profesores centran su interés en dar respuesta a las circunstancias de dicho contexto y a las necesidades que de él se derivan. Esta situación origina conflictos, ya que todos los centros no necesitan la misma distribución del tiempo y repercute negativamente en su organización y proceso educativo.

Tampoco hay que olvidar el reto que suponen las TIC en la organización del espacio y del tiempo educativos. Uno de los mayores desafíos que afectan a los espacios y tiempos educativos es la competencia de los nuevos modelos de educación con movimientos como la escuela en el hogar, que se opone a los modelos tradicionales de aprendizaje, o el aprendizaje en línea, que hace referencia a las oportunidades educativas formales e informales en Internet y que transforman la organización del espacio y el tiempo al producirse en cualquier momento y lugar (INTEF, 2014).

Los alumnos de altas capacidades se verían más favorecidos por entornos de aprendizaje con fuerte presencia tecnológica. Vázquez Cano y Sevillano García (2015) señalan que, frente a los entornos tradicionales, aquellos favorecen más el desarrollo de las capacidades de orden superior, la motivación para el aprendizaje y el trabajo en equipo.

\section{ESTUDiO DE CAMPO: EL CUESTIONARIO Y SUS RESUlTADOS}

En este apartado nos referimos al proceso de elaboración del cuestionario, a su aplicación y a los resultados obtenidos. Como hemos señalado en los puntos anteriores, el cuestionario se basa en los referentes normativos, conceptuales y de 
organización escolar expuestos en los apartados anteriores y resumidos en la Tabla 1 y en las Ilustraciones 1 y 2 .

\subsection{Población y muestra}

La investigación se ha desarrollado en la provincia de Palencia perteneciente a la Comunidad Autónoma de Castilla y León. Según las estadísticas de esta región (MECD, 2016) en el curso 2014/2015, la población de centros y profesores de EP eran las siguientes:

TABLA 7

Población de centros y profesores de EP en Castilla y León y Palencia

\begin{tabular}{|l|c|c|c|c|}
\hline \multirow{2}{*}{\multicolumn{1}{|c|}{ EDUCACIÓN PRIMARIA }} & \multicolumn{2}{|c|}{ CASTILLA Y LEÓN } & \multicolumn{2}{c|}{ PALENCIA } \\
\cline { 2 - 5 } & $\mathbf{N}$ & $\%$ & $\mathbf{N}$ & $\%$ \\
\hline Centros Públicos & 664 & 79,33 & 53 & 82,81 \\
\hline Centros Privados Concertados & 173 & 20,67 & 11 & 17,19 \\
\hline TOTALES & 837 & 100 & 64 & 100 \\
\hline Profesorado Centros Públicos & 12722 & 82,36 & 869 & 79,07 \\
\hline $\begin{array}{l}\text { Profesorado Centros } \\
\text { Privados Concertados }\end{array}$ & 2725 & 17,64 & 230 & 20,93 \\
\hline TOTALES & 15447 & 100 & 1099 & 100 \\
\hline
\end{tabular}

De esta población se ha elegido una muestra representativa de los centros y profesores de la provincia de Palencia. Los expertos recomiendan seleccionar un muestreo del 10-20\% de la población (Cardona, 2002).

El método de selección ha sido el muestreo probabilístico estratificado en el que los estratos son los sectores de intervención de los Equipos de Orientación Educativa (EOE) establecidos en la Orden de 9 de diciembre de 1992: demográfico, geográfico, pedagógico y de coordinación. Los estratos resultantes han sido los siguientes: 
INFLUENCIA DE LA ORGANIZACIÓN ESCOLAR EN LA EDUCACIÓN

DE LOS ALUMNOS DE ALTAS CAPACIDADES

TABLA 8

Estratos resultantes según los sectores de intervención de los EOE

\begin{tabular}{|l|c|c|}
\hline & \multicolumn{2}{|c|}{ TiPO DE CENTRO } \\
\hline \multicolumn{1}{|c|}{ Equipos De OrIENTACIÓn EduCATIVA } & PÚBLICO & CONCERTADO \\
\hline Palencia & 17 & 10 \\
\hline Venta de Baños & 9 & 0 \\
\hline Carrión de los Condes & 10 & 0 \\
\hline Guardo & 10 & 0 \\
\hline Aguilar de Campoo & 7 & 1 \\
\hline TOTALES & 53 & 11 \\
\hline
\end{tabular}

Sobre esta base, la muestra obtenida ha sido de 166 profesores, el 15,10\% de la población. Presenta las siguientes características:

TABLA 9

Distribución de la muestra según diversos criterios

\begin{tabular}{|c|c|c|c|}
\hline \multicolumn{2}{|c|}{ DATOS DE LA MUESTRA } & FRECUENCIA & PORCENTAJE \\
\hline \multirow[t]{3}{*}{ Ubicación geográfica } & Rural & 102 & 61,4 \\
\hline & Urbano & 64 & 38,6 \\
\hline & Total & 166 & 100,0 \\
\hline \multirow[t]{3}{*}{ Tipo de centro (profesores) } & Público & 132 & 79,5 \\
\hline & Concertado & 34 & 20,5 \\
\hline & Total & 166 & 100,0 \\
\hline \multirow[t]{3}{*}{ Género } & Masculino & 35 & 21,1 \\
\hline & Femenino & 131 & 78,9 \\
\hline & Total & 166 & 100,0 \\
\hline \multirow[t]{5}{*}{ Años de experiencia docente } & $1-10$ & 71 & 42,8 \\
\hline & $11-20$ & 43 & 25,9 \\
\hline & $21-30$ & 25 & 15,1 \\
\hline & +30 & 27 & 16,3 \\
\hline & Total & 166 & 100,0 \\
\hline
\end{tabular}


L. PÉREZ DÍEZ Y C. JIMÉNEZ FERNÁNDEZ

INFLUENCIA DE LA ORGANIZACIÓN ESCOLAR EN LA EDUCACIÓN

DE LOS ALUMNOS DE ALTAS CAPACIDADES

\begin{tabular}{|c|c|c|c|}
\hline \multicolumn{2}{|l|}{ DATOS DE LA MUESTRA } & FRECUENCIA & PORCENTAJE \\
\hline \multirow{7}{*}{$\begin{array}{l}\text { Estar en posesión de formación } \\
\text { relacionada con la alta capacidad }\end{array}$} & No & 59 & 35,5 \\
\hline & Sí, sin especificar & 4 & 2,4 \\
\hline & En la carrera & 41 & 24,7 \\
\hline & $\begin{array}{c}\text { Cursos después } \\
\text { de la carrera }\end{array}$ & 16 & 9,6 \\
\hline & Otras titulaciones & 13 & 7,8 \\
\hline & $\begin{array}{l}\text { Formación } \\
\text { múltiple }\end{array}$ & 33 & 19,9 \\
\hline & Total & 166 & 100,0 \\
\hline \multirow{3}{*}{$\begin{array}{l}\text { Experiencia con alumnos de altas } \\
\text { capacidades }\end{array}$} & No & 113 & 68,1 \\
\hline & Sí & 53 & 31,9 \\
\hline & Total & 166 & 100,0 \\
\hline
\end{tabular}

Cabe destacar que en ella predominan los profesores del medio rural $(61,4 \%)$, los centros públicos (79,5\%), las mujeres (78,9\%), los que tienen entre 1 y 10 años de experiencia docente $(42,8 \%)$, y los que señalan carecer de experiencia $(68,1 \%)$ y formación $(35,5 \%)$ sobre los alumnos de alta capacidad.

\subsection{El cuestionario como instrumento de recogida de información}

En la definición del constructo a medir y cara a precisar la fiabilidad y validez del cuestionario, se ha explicitado a los profesores que componen la muestra cuál es su finalidad, estructura, contenido y procedimiento para plasmar las respuestas.

Consta de los siguientes bloques de contenido:

1. Normativa estatal y autonómica que regula la EP, la atención a la diversidad y la inclusión educativa. Se resumen en la Tabla 1.

2. Dimensiones organizativas. La práctica educativa se sustenta en la estructura organizativa de los centros mediante diferentes componentes que inciden en la educación de los más capaces. Se resumen en la Ilustración 2.

3. Normativa, estructura y atención a la diversidad de los más capaces. El establecimiento de los vínculos entre estos elementos relaciona la práctica educativa con los más capaces y la calidad educativa desde la perspectiva de la diferencia. Se plasma en la Ilustración 3. 
ILUSTRACIÓN 3

Vínculos entre la organización educativa, los principios educativos incluidos en la normativa y la intervención con los más capaces
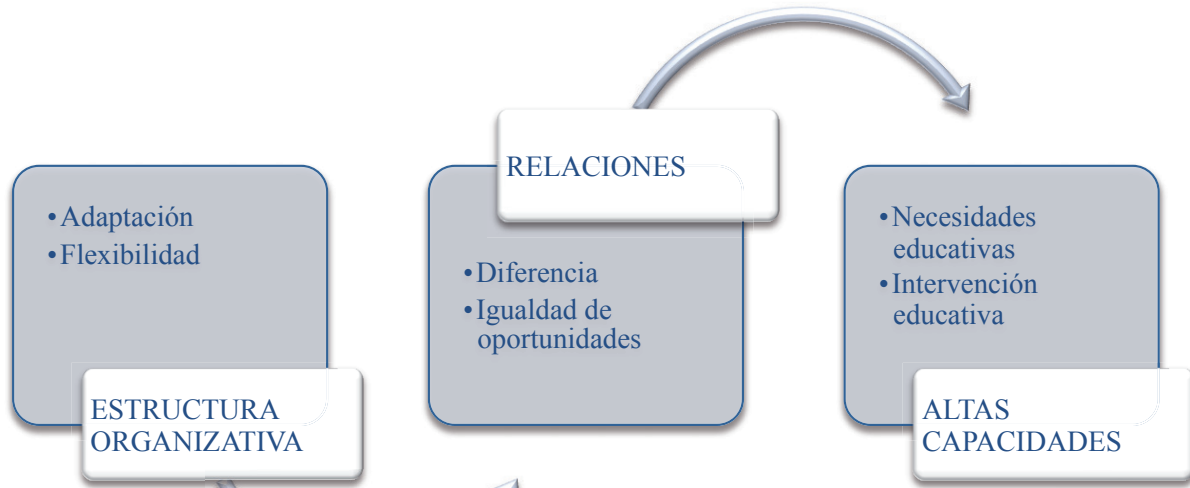

Consta de tres tipos de preguntas. Un primer bloque de 12 cuestiones sobre las denominadas variables de clasificación que permiten caracterizar la muestra resultante. Un segundo grupo de 30 preguntas (1-30) que constituyen el cuerpo del cuestionario valoradas mediante una escala Likert de 4 niveles: nada de acuerdo, poco de acuerdo, bastante de acuerdo, totalmente de acuerdo. Un último grupo (31-37) con 7 preguntas de respuesta semiabierta que se responden en función de la formación y experiencia docente.

Para validar el cuestionario se seleccionaron diez expertos con el objetivo de comprobar si los ítems de cada uno de los bloques del cuestionario recogían información válida según los objetivos establecidos y los contenidos asociados a los mismos. Las cualificaciones profesionales de los expertos era la siguiente:

- 1 orientador de Instituto de Educación Secundaria Obligatoria (IES)

- 1 especialista en Pedagogía Terapéutica (PT) de IES

- 2 directores de EOE (Equipo de Orientación Educativa)

- 1 orientador de EOE

- 1 maestro de Primaria de Centro Privado-Concertado

- 1 profesora Técnico de Servicios a la Comunidad (PTSC) de IES

- 1 asesora de Atención a la Diversidad

- 1 directora de un Centro Público de Primaria

- 1 profesora Técnico de Servicios a la Comunidad de EOE

Depurada la versión inicial del cuestionario con las observaciones de los expertos, se procedió a administrarlo a la muestra de profesores según el siguiente 
procedimiento: 1) En mayo de 2015 se entregaron los cuestionarios a los directores de los EOE y de los centros concertados invitándolos a agilizar su cumplimentación. 2) En junio de 2015 se recogieron. 3) En julio de dicho año se registraron las respuestas dadas en el programa informático spss para su tratamiento posterior.

La fiabilidad del cuestionario se ha calculado mediante el coeficiente Alfa de Cronbach alcanzando un índice de 0,739.

\subsection{Exposición de resultados}

Para los 30 primeros ítems, los porcentajes de respuesta obtenidos fueron los siguientes:

\section{GRÁFICO 2}

Porcentajes de frecuencias de los 30 ítems respondidos mediante escala Likert

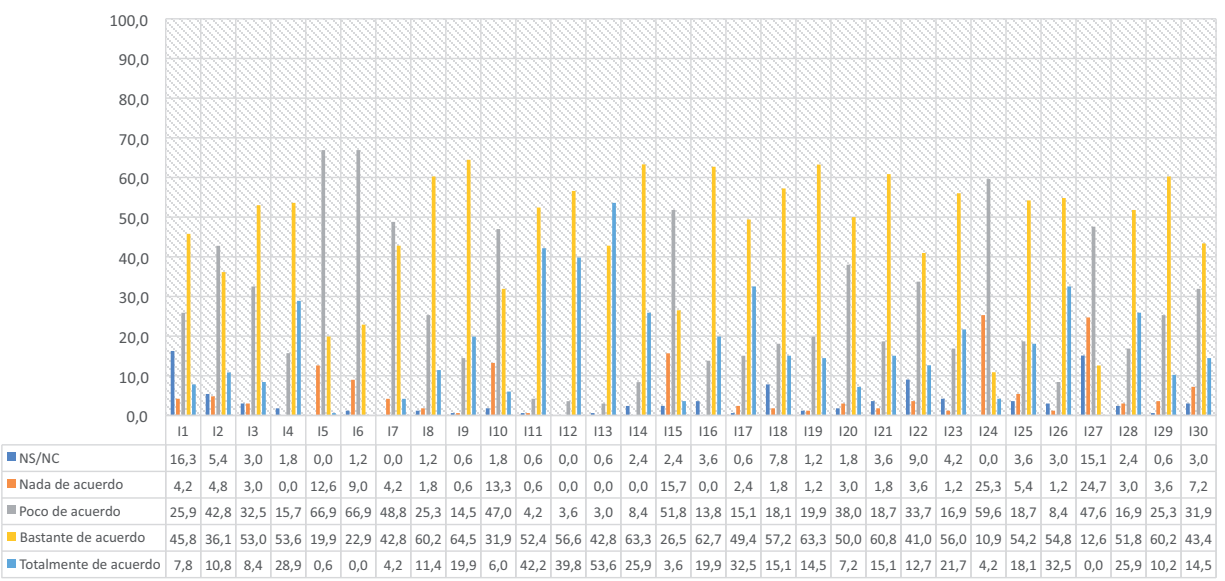

Según estos resultados, el mayor grado de acuerdo (bastante de acuerdo y totalmente de acuerdo) se produce en los ítems 1, 3, 4, 8, 9, 11, 12, 13, 14, $16,17,18,19,20,21,22,23,25,26,28,29$ y 30 . Esto indica que a juicio de los encuestados:

- La normativa sobre alta capacidad no favorece la emergencia del talento y la capacidad.

- La educación inclusiva favorece la intervención con los alumnos de altas capacidades, pero es un planteamiento alejado de las propuestas y actuaciones de los centros educativos.

- El Proyecto Educativo y el Plan de Acción a la Diversidad son documentos clave para adaptarse a las diferencias individuales del alumno. 
- La individualización de la enseñanza flexibiliza la estructura organizativa de los centros educativos y contribuye a la mejora de la intervención con los alumnos más capaces.

- El conflicto entre la individualización de la enseñanza y el agrupamiento por edades incide negativamente en las oportunidades de aprendizaje ofrecidas al alumnado de altas capacidades.

- La intervención con alumnos de altas capacidades se ve favorecida cuando se potencia la coordinación entre profesores y se les cualifica profesionalmente, cuando la administración educativa apoya la actuación del profesorado en la identificación de estos alumnos y cuando la acción directiva facilita las relaciones con la administración, la implicación del profesorado y lidera planes de actuación para los más capaces.

- Son necesarias alternativas a la discontinuidad y fragmentación de las actividades de las áreas curriculares para favorecer el ritmo de aprendizaje de los alumnos de altas capacidades.

- La organización de los centros educativos propicia una enseñanza orientada al alumno medio sin capacidad para impulsar al alumnado a los niveles más altos de rendimiento.

- La organización de los espacios escolares limita la flexibilidad de la respuesta educativa a los alumnos más capaces.

- La definición del tiempo es anterior a la actividad educativa y no se ajusta a las necesidades educativas de los alumnos más capaces.

- Primero se enriquecen las actividades educativas para los alumnos con altas capacidades y luego se priorizan los tiempos de ejecución.

- Los horarios semanales de las áreas del currículo no favorecen la intervención con alumnos de altas capacidades.

- La estructura organizativa de la escuela actual es un obstáculo para la emergencia del talento y la capacidad.

- El sistema educativo debe proporcionar acceso a todos los niveles del currículo para que los más capaces progresen libremente por ellos.

- La priorización en las dificultades de aprendizaje afecta a la calidad de las intervenciones con los alumnos más capaces.

- Los centros educativos organizan sus recursos para facilitar el aprendizaje de todos los alumnos y a la vez individualizan la enseñanza considerando las necesidades de cada uno.

- Los centros educativos son lugares adecuados para responder a las necesidades educativas de los más capaces.

La mayor igualdad se produce en el ítem 2 en el que el planteamiento es que el principio de atención a la diversidad recogido en la LOE y en la LOMCE alcanza a todo el alumnado, incluido el de altas capacidades.

Por último, el menor grado de acuerdo (nada de acuerdo y poco de acuerdo) se produce en los ítems 5, 6, 7, 10, 15, 24 y 27 y se pone de manifiesto en los siguientes elementos: 
L. PÉREZ DÍEZ Y C. JIMÉNEZ FERNÁNDEZ

INFLUENCIA DE LA ORGANIZACIÓN ESCOLAR EN LA EDUCACIÓN

DE LOS ALUMNOS DE ALTAS CAPACIDADES

- La estructura del sistema educativo es suficientemente flexible como para adaptarse a la diversidad del todo el alumnado, incluido el de altas capacidades.

- La flexibilización es suficiente para atender a los alumnos de altas capacidades.

- Las propuestas educativas para los alumnos de altas capacidades fuera del horario escolar sirven para compensar las carencias en intervención que se producen en dicho horario.

- El tiempo asignado en el horario semanal para cada área facilita la intervención con los alumnos de altas capacidades.

- La formación y la preparación del profesorado son adecuadas para intervenir con alumnos de altas capacidades.

- La atención al alumnado de altas capacidades en nuestro sistema educativo permite un desarrollo de todo su potencial.

Los casos en los que se produce la opción "no sabe, no contesta" tienen un máximo en el ítem $1(16,3 \%)$ y un mínimo en los ítems 5, 7, 12 y 24 con ningún caso.

Finalmente, en los ítems del 31 al 37 o de respuesta semiabierta los resultados son los siguientes: 
INFLUENCIA DE LA ORGANIZACIÓN ESCOLAR EN LA EDUCACIÓN

DE LOS ALUMNOS DE ALTAS CAPACIDADES

GRÁFICO 3

Resultados de los ítems del cuestionario respondidos mediante opción múltiple

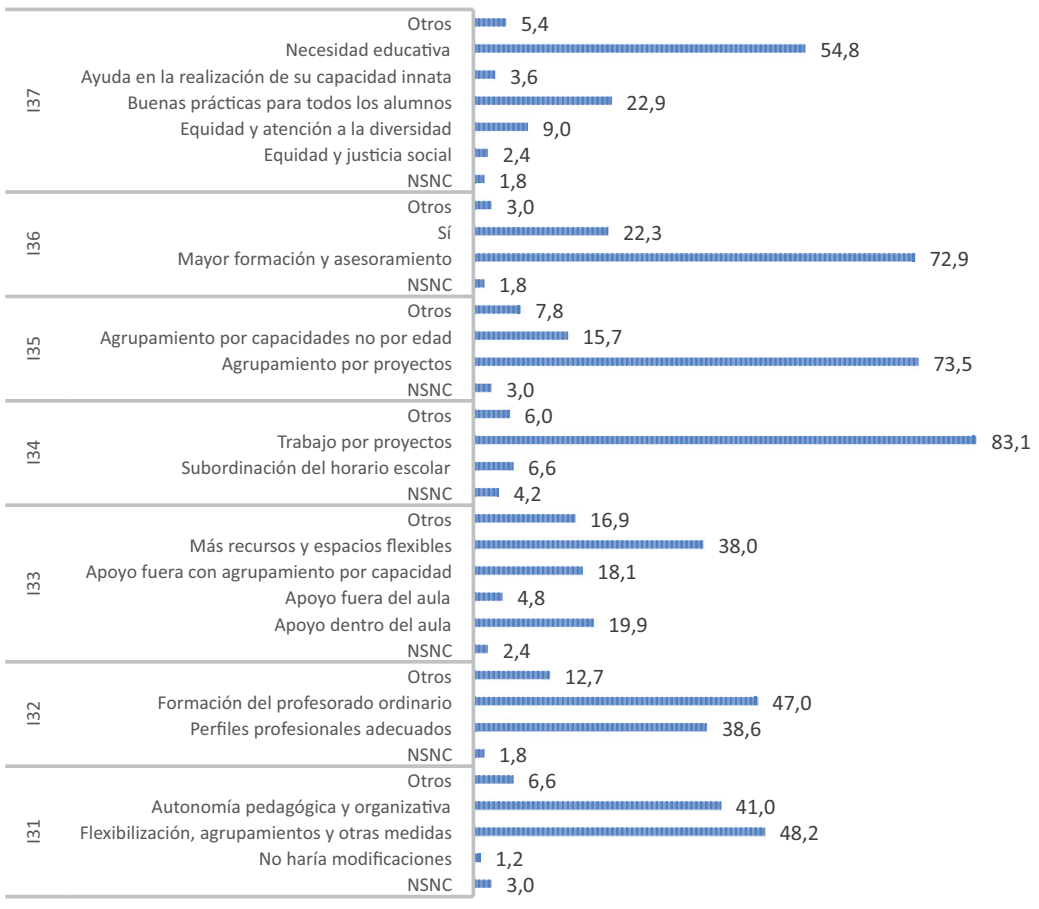

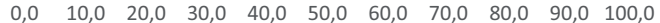

Estos resultados pueden resumirse como sigue:

- La mejor definición del concepto de atención a los más capaces es su planteamiento como necesidad educativa.

- Los profesores necesitan más formación, asesoramiento y apoyo para atender eficazmente a los más capaces.

- La mejor propuesta de agrupamiento de los alumnos de altas capacidades es el trabajo por proyectos para poder progresar según su ritmo de aprendizaje.

- El trabajo por proyectos también es la propuesta elegida para modificar el horario de forma flexible y atender a los más capaces.

- Para que el trabajo en el aula favorezca la enseñanza del alumnado de altas capacidades es necesaria una mayor dotación de recursos materiales y espacios más flexibles. 
L. PÉREZ DÍEZ Y C. JIMÉNEZ FERNÁNDEZ

INFLUENCIA DE LA ORGANIZACIÓN ESCOLAR EN LA EDUCACIÓN

DE LOS ALUMNOS DE ALTAS CAPACIDADES

- La normativa educativa debería concretar otras medidas organizativas para la intervención con el alumnado de altas capacidades además de la flexibilización educativa y los agrupamientos.

\section{CONCLUSIONES Y ORIENTACIONES PARA LA PRÁCTICA EDUCATIVA}

La existencia de una normativa que hace visibles a los más capaces en los centros escolares y en el sistema educativo no significa que la educación real dé respuesta adecuada a sus necesidades de aprendizaje.

Convendría revisar la legislación educativa para que impulse y apoye una estructura organizativa en el sistema educativo y en los centros que no dificulte la educación de los alumnos de altas capacidades.

La normativa quizá debería plantear una definición amplia y operativa de la alta capacidad que marque ciertos lineamientos y topes a los procedimientos de identificación e intervención. También debe optimizarse la estructura organizativa para que dé una respuesta más eficaz a las necesidades educativas de estos alumnos. Aumentar la autonomía organizativa de los centros escolares con su correspondiente rendición de cuentas podría ser una opción adecuada.

El profesorado debe conocer la normativa, el alcance del concepto de alta capacidad y las intervenciones que pueden realizarse en los centros educativos con estos alumnos. Sin embargo, el $68,1 \%$ de los encuestados señala que carece de experiencia sobre alumnos de alta capacidad y el $35,5 \%$ indica que no tiene formación al respecto.

Respecto a la identificación, es necesario tener en cuenta los siguientes elementos que permitan subsanar los déficits en los resultados de los diferentes cursos académicos (MECD, 2015):

- Desarrollar estrategias fundamentadas en la utilización de múltiples criterios complementarios, que produzcan datos procedentes de medidas contrastadas y fuentes diversas, pertinentes y periódicamente revisables.

- Utilizar instrumentos válidos y fiables y con una baremación ajustada a la población a la que se dirigen.

- Considerar la identificación como un proceso continuo y revisable antes que como una valoración tajante sobre si un estudiante tiene altas capacidades o no.

- Para subsanar las carencias formativas el profesorado necesita formación específica en los procesos de identificación e intervención con estos alumnos. Esta formación no puede limitarse al momento inicial de su carrera profesional, también debe centrarse en cómo aprender de la experiencia y en cómo construir su conocimiento profesional (Palomares, 2010).

Respecto a la intervención, esta debe producirse dentro de una estructura organizativa que pueda reorientarse en función de las necesidades de su alumnado 
(Moreno Cerrillo, 2007), siendo su característica principal la flexibilidad en los agrupamientos del alumnado, organización del profesorado, espacios y tiempo.

Igualmente importante es la coordinación docente como proceso favorecedor de la intervención con los alumnos de altas capacidades, pero en condiciones organizativas caracterizadas por disponer de espacios apropiados, tiempos suficientes y una flexibilidad que permita una educación ajustada a sus necesidades.

Según el cuestionario, el profesorado prefiere el agrupamiento para el trabajo por proyectos más que por otras variables como la edad cronológica o la capacidad intelectual, que ha sido una opción minoritaria. No obstante, el agrupar por capacidad debe ser objeto de reflexión ya que hay investigaciones que concluyen que hay mejoras en el rendimiento académico de los más capaces cuando están agrupados de esta forma (Michael, Matthews, Ritchotte y McBee, 2013), bien con alumnos de similar edad o en grupos multiedad que tienden a homogeneizar la capacidad. Sin olvidar que los alumnos de altas capacidades necesitan relacionarse con sus iguales en edad para socializarse y desarrollar las competencias básicas del aprendizaje diario (Winebrenner y Brulles, 2008). La forma de agrupamiento no tiene por qué tener un carácter fijo a lo largo del curso escolar.

El agrupamiento del alumnado está influenciado por el espacio en el que se produce su educación, si es flexible y funcional posibilitará cambios en las dimensiones de los grupos, proporcionará lugares para el trabajo personal y el uso de materiales específicos para un aprendizaje más óptimo en función del objetivo que se persigue en cada caso.

Respecto a la organización del tiempo, la administración educativa debe tomar conciencia de que los horarios fijos semanales imponen ritmos artificiales independientes de los ritmos de los alumnos, y que la fragmentación de las asignaturas dificulta el proceso de síntesis y globalización de conocimientos tan necesarios para el alumnado de altas capacidades. La respuesta está en la flexibilización de los tiempos asignados a la educación de estos alumnos en cuanto a la adquisición de objetivos, actividades realizadas, materiales utilizados y agrupamientos previstos.

La mayoría del profesorado que respondió al cuestionario percibió que la inclusión educativa favorece la intervención con los alumnos más capaces.

\section{REFERENCIAS BIBLIOGRÁFICAS}

Adelson, J. L.; McCoach, D. B. y Gavin, M. K. (2012). Examining the effects of gifted programming in mathematics and reading using the ECLS-K. Gifted Child Quarterly, 56, 25-39. doi: 10.1177/001698211431487.

Antúnez, S. y Gairín, J. (1996). La organización escolar. Práctica y fundamentos. Barcelona: Graó.

Aznar, I.; Cáceres, M. P.; Pérez, R. e Hinojo, F. R. (2014). El profesorado en los centros educativos. Modelos organizativos. En Isabel Cantón y Margarita Pino (Coords.). Organización de Centros educativos en la sociedad del conocimiento (pp. 39-63). Madrid: Alianza. 
L. PÉREZ DÍEZ Y C. JIMÉNEZ FERNÁNDEZ

INFLUENCIA DE LA ORGANIZACIÓN ESCOLAR EN LA EDUCACIÓN

DE LOS ALUMNOS DE ALTAS CAPACIDADES

Brody, L. E. (2015). The Julian C. Stanley Study of Exceptional Talent: Una aproximación personalizada para dar respuesta a las necesidades de los estudiantes con altas capacidades. Revista de Educación, 368, 297. doi: 10.4438/1988-592X-RE-2015-368-292. Descargado el día 9 de abril de 2015. http://www.mecd.gob.es/dctm/revista-de-educacion/articuloscastellano/ultimas-versiones/rev368-espanol-final.pdf?documentI$\mathrm{d}=0901 \mathrm{e} 72 \mathrm{~b} 81 \mathrm{cba} 4 \mathrm{~d} 8$.

Calatayud, M. A. (2014). Organización de alumnos en el aula. En Isabel Cantón y Margarita Pino (Coords.). Organización de Centros educativos en la sociedad del conocimiento (pp. 89-102). Madrid: Alianza.

Cardona, J. (2008). Aprendizajes acumulativo y generativo de las organizaciones educativas. Revista Educación, 32 (2), 73-84. doi: http://dx.doi.org/10.15517/revedu.v32i2.517. Descargado el 29 de mayo de 2016. http://revistas.ucr.ac.cr/index.php/educacion/ article/view/517/539.

Cardona, M. C. (2002). Introducción a los métodos de investigación en educación. Madrid: EOS.

Comité Económico y Social Europeo (2012). Liberar el potencial de los niños y los jóvenes con gran capacidad intelectual. Descargado el 9 de diciembre de 2014. http://www. fundacionpryconsa.es/pdf/Pleno.pdf.

Domènech, J. y Viñas, J. (1997). La organización del espacio y del tiempo en el centro educativo. Barcelona: Graó.

Freeman, J. (2015). Por qué algunos niños con altas capacidades son notablemente más exitosos en la vida que otros con iguales oportunidades y habilidad. Revista de Educación, 368, 255-278. doi: 10.4438/1988-592X-RE-2015-368-291. Descargado el 9 de abril de 2015. http://www.mecd.gob.es/dctm/revista-de-educacion/articuloscastellano/ ultimas-versiones/rev368-espanol-final.pdf?documentId=0901e72b81cba4d8.

Gagné, F. (2015). De los genes al talento: la perspectiva DMGT/CMTD. Revista de Educación, 368, 12-39. doi: 10.4438/1988-592X-RE-2015-368-289. Descargado el 9 de abril de 2015. http://www.mecd.gob.es/dctm/revista-de-educacion/articuloscastellano/ultimas-versiones/rev368-espanol-final.pdf?documentId=0901e72b81cba4d8.

Gairín, J. y Rodríguez, D. (2011). Cambio y mejora en las organizaciones educativas. Educar, 47 (1), 31-50. ISSN: 0211-819X. Descargada el 15 de febrero de 2017. http://ddd.uab.cat/ pub/educar/0211819Xv47n1/0211819Xv47n1p31.pdf.

Hayes, H. (2014). Currículum XXI. Lo esencial de la educación para un mundo en cambio. Madrid: Narcea.

Hernández Torrano, D. y Gutiérrez Sánchez, M. (2014). El estudio de la alta capacidad intelectual en España: Análisis de la situación actual. Revista de Educación, 364, 251-272. doi: 10.4438/1988-592X-RE-2014-364-261. Descargado el 1 de febrero de 2015. http://www.mecd.gob.es/dctm/revista-de-educacion/doi/364261.pdf?documentId $=0901 \mathrm{e} 72 \mathrm{~b} 8185 \mathrm{dc} 09$.

Instituto Nacional de Tecnologías Educativas y de Formación del Profesorado (2014). Resumen Informe Horizon 2014. EP y Secundaria. Descargado el 7 de abril de 2017. http:// blog.educalab.es/intef/wp-content/uploads/sites/4/2014/11/Resumen_Informe_Horizon_NMC_2014_K12_INTEF_octubre_2014.pdf.

Instituto Nacional de Tecnologías Educativas y de Formación del Profesorado (2016). Resumen Informe Horizon. Edición 2016. EP y Secundaria. Descargado el 7 de abril de 2017. http://blog.educalab.es/intef/wp-content/uploads/sites/4/2016/10/2016_1018_ Resumen_Horizon_Primaria_Secundaria_2016_INTEF.pdf. 
Jiménez Fernández, C. (2010). Diagnóstico y educación de los más capaces. Madrid: Pearson. Kulik, J. A. (2002). Grouping and Tracking. En N. Colangelo y G. A. Davis (Eds.). Handbook of Gifted Education. Massachusetts: Allyn and Bacon. Segunda edición.

Mandelman, S. D.; Tan, M.; Aljughaiman, A. M. y Grigorenko, E. L. (2010). Intellectual giftedness: economic, political, cultural and psychological considerations. Learning and Individual Differences, 20, 287-297. Descargado el 13 de mayo de 2015. http://www. researchgate.net/profile/Mei_Tan2/publication/222299529_Intellectual_giftedness_ Economic_political_cultural_and_psychological_considerations/links/5407c0d90cf23d9765ae1aeb.pdf.

Matthews, M. S.; Ritchotte, J. A. y T. McBee, M. (2013). Effects of schoolwide cluster grouping and within-class ability grouping on elementary school students' academic achievement growth. High Ability Studies, 24:2, 81-97. Descargado el 27 de febrero de 2015. http:// dx.doi.org/10.1080/13598139.2013.846251.

MECD (2014). PISA 2012. Informe Español. Resultados y Contexto. Descargado el 12 de febrero de 2014. http://www.mecd.gob.es/dctm/inee/internacional/pisa2012/pisa2012. pdf?documentId=0901e $72 \mathrm{~b} 8195 \mathrm{~d} 643$.

MECD. Ley Orgánica 8/2013, de 9 de diciembre, para la mejora de la calidad educativa. $B O E$, 10/12/2013.

Ministerio de Educación, Cultura y Deporte (MECD). Estadísticas de la educación no universitaria. Descargado el 12 de febrero de 2016. http://www.mecd.gob.es/servicios-al-ciudadano-mecd/estadisticas/educacion/no-universitaria.html.

Ministerio de Educación y Ciencia. Ley Orgánica 2/2006, de 3 de mayo, de Educación. BOE, 04/05/2006. Descargado el 7 de marzo de 2015. https://www.boe.es/buscar/doc.php?i$\mathrm{d}=$ BOE-A-2006-7899.

Orden de 9 de diciembre de 1992 por la que se regula la estructura y funciones de los Equipos de Orientación Educativa y Psicopedagógica. Boletín Oficial del Estado, 303, 18 de diciembre de 1992.

Orden EDU/283/2007 por la que se constituyen el Centro de recursos de educación intercultural, el Equipo de atención al alumnado con superdotación intelectual y tres equipos de atención al alumnado con trastornos de conducta. Boletín Oficial de Castilla y León, 40, 26 de febrero de 2007. Descargado el 4 de julio de 2015. http://www.educa.jcyl.es/ es/resumenbocyl/orden-edu-283-2007-19-febrero-constituyen-centro-recursos-e.ficheros/68799-1.pdf.

Orden EDU/519/2014, de 17 de junio por la que se establece el currículo y se regula la implantación, evaluación y desarrollo de la EP en la Comunidad Autónoma de Castilla y León. BOCYL, 117, 20 de junio de 2014.

Palomares Ruiz, A. (2010). El Nuevo modelo docente en el paradigma formativo centrado en el alumnado. Enseñanza E Teaching: Revista Interuniversitaria de Didáctica, 27 (2), 44-75. Descargado el 19 de julio de 2017. http://revistas.usal.es/index.php/0212-5374/ article/view/7095/7519.

Pérez, R. (2014). Teorías organizativas. La escuela como organización. En Isabel Cantón y Margarita Pino (Coords.). Organización de Centros educativos en la sociedad del conocimiento (pp. 39-63). Madrid: Alianza.

Renzulli, J. S. y Gaesser, A. H. (2015). Un sistema multicriterial para la identificación del alumnado de alto rendimiento y de alta capacidad creativo-productiva. Revista de Educación, 368, 96-131. doi: 10.4438/1988-592X-RE-2015-368-290. Descargado el 9 de 
L. PÉREZ DÍEZ Y C. JIMÉNEZ FERNÁNDEZ

INFLUENCIA DE LA ORGANIZACIÓN ESCOLAR EN LA EDUCACIÓN

DE LOS ALUMNOS DE ALTAS CAPACIDADES

abril de 2015. http://www.mecd.gob.es/dctm/revista-de-educacion/articuloscastellano/ ultimas-versiones/rev368-espanol-final.pdf?documentId=0901e72b81cba4d8.

Román, M. (2014). Aprender a programar 'apps' como enriquecimiento curricular en alumnado de alta capacidad. Bordón. Revista de Pedagogía, 66 (4), 135-155. Disponible en http://dialnet.unirioja.es/descarga/articulo/4821741.pdf.

Steenbergen-Hu, S.; Makel, M. C. y Olszewski-Kubilius, P. (2016). What One Hundred Years of Research Says About the Effects of Ability Grouping and Acceleration on K-12 Students' Academic Achievement: Findings of Two Second-Order Meta-Analyses. Review of Educational Research, 86 (4). doi: 10.3102/0034654316675417. Descargado el 15 de marzo de 2017. http://journals.sagepub.com/doi/full/10.3102/0034654316675417.

Tourón, J. y Santiago, R. (2015). El modelo Flipped Learning y el desarrollo del talento en la escuela. Revista de Educación, 368, 196-231. doi: 10.4438/1988-592X-RE-2015-368-288. Descargado el 9 de abril de 2015, http://www.mecd.gob.es/dctm/revista-de-educacion/ articuloscastellano/ultimas-versiones/rev368-espanol-final.pdf?documentId=0901e72b$81 \mathrm{cba} 4 \mathrm{~d} 8$.

Universidad de Barcelona (2015). INCLUDE-ED. Estrategias para la inclusión y cohesión social en Europa a partir de la Educación. Descargado el 27 de enero 2016. http://www. comunidadedeaprendizagem.com/uploads/materials/325/46bb06d7b924192b2b69f299d485ce7e.pdf.

Vázquez Cano, E. y Sevillano García, M. L. (2015). Analysis of risks in a Learning Management System: A case study in the Spanish National University of Distance Education (UNED). Journal of New Approaches in Educational Research, 4 (1), 62-68. doi: http:// dx.doi.org/10.7821/naer.2015.1.107. Descargado el 28 de julio de 2017. https://naerjournal.ua.es/article/view/v4n1-9.

Walker, Ch. L.; Shore, B. M. y French, L. R. (2011). A theoretical context for examining students' preference across ability levels for learning alone or in groups. High Ability Studies, 22:1, 119-141. doi: 10.1080/13598139.2011.576082. Descargado el 27 de febrero de 2015. http://dx.doi.org/10.1080/13598139.2011.576082.

Winebrenner, S. y Brulles, D. (2008). The Cluster Grouping Handbook: A Schoolwide Model: How to Challege Gifted and Improve Achivement for All. Free Spirit Publishing. 